\title{
Place of birth, cancer beliefs and being current with colon cancer screening among US adults
}

\author{
Kolapo A. Idowua , Babafemi Adenuga , Oritsetsemaye Otubua , Krishnan Narasimhana, \\ Feremusu Kamara ${ }^{a}$, Finie Hunter-Richardson ${ }^{a}$, Daniel Larbib, Zaki A. Sherifc, Adeyinka O. Laiyemo ${ }^{b}$ \\ Howard University College of Medicine, Washington, DC, USA
}

\section{Abstract}

Departments of a Community and Family Medicine (Kolapo A. Idowu, Babafemi Adenuga, Oritsetsemaye Otubu, Krishnan Narasimhan, Feremusu Kamara, Finie Hunter-Richardson); ${ }^{b}$ Medicine (Daniel Larbi, Adeyinka O. Laiyemo); 'Biochemistry and Molecular Biology (Zaki A. Sherif), Howard University College of Medicine, Washington DC, USA

\section{Conflict of Interest: None}

Correspondence to: Adeyinka O. Laiyemo, MD, MPH, Division of Gastroenterology, Department of Medicine, Howard University College of Medicine, 2041 Georgia Avenue, NW, Washington DC 20060, USA, Tel.: +1 202865 7186, Fax: +1 202865 4607,

e-mail: adeyinka.laiyemo@howard.edu

Received 20 January 2016; accepted 9 April 2016; published online 25 April 2016

DOI: http://dx.doi.org/10.20524/aog.2016.0040

Grant support: Dr Laiyemo was supported by grant awards from Charles and Mary Latham Funds, the National Center for Advancing Translational Science, (Grant Number: 1KL2TR001432-01) and from the National Institute for Diabetes, Digestive Diseases and Kidney
(Grant Number: R21DK100875), National Institutes of Health. The funding source did not play any role in the study or in the decision to submit the article for publication.

Other disclosure: An abstract of the study was presented during the American College of Gastroenterology meeting in San Diego California in October 2013 and at the annual meeting of the District of Columbia Academy of Family Physician in November 2013.

\section{Introduction}

Approximately four decades ago, studies suggested that Japanese immigrants acquired the risk of colorectal cancer (CRC) as Caucasians in Hawaii within the same generation [1]. This was before the advent of widespread CRC screening in the United States. Access and utilization of screening are known to affect CRC burden [2]. Factors associated with low uptake of CRC screening include low socioeconomic status, lack of or inadequate insurance coverage, low literacy level, and low 
perceived cancer risk [3-5]. Using data from the 1998 National Health Interview Survey (NHIS), Goel et al [6] reported a nonsignificant reduced odds of prior fecal occult blood testing (FOBT) and sigmoidoscopy use among foreign- versus USborn respondents. This was in the pre-colonoscopy screening era and colonoscopy is fast becoming the dominant CRC screening modality in the United States $[7,8]$.

Beliefs about the cause of a particular disease can influence whether and how an individual takes steps to reduce the risk of developing that disease [9]. Powe reported that fatalism (attitude of perceiving everything as being ordained by fate) was associated with lower uptake of FOBT among 192 study participants [10]. In the present study we evaluated the association of place of birth (US- versus foreign-born) and cancer beliefs with being current with CRC screening guidelines using FOBT, sigmoidoscopy and colonoscopy.

\section{Materials and methods}

\section{Health information national trends survey (HINTS)}

We used data from 2007 HINTS, a probability-based sample survey of US adults conducted by National Cancer Institute in 2008. The details of HINTS have been published [11]. In summary, HINTS evaluated heath communication, cancerrelated information, beliefs and behavior of adults in the United States. The survey used stratified clustered sampling and utilized a dual-frame design that combined random digital dial telephone survey $(n=4,092)$ with mailed survey using a national listing of addresses available from the United States Postal Service $(n=3,582)$. Interviews were conducted in English or Spanish. Surnames were used to identify probable Hispanic correspondents which allowed first contact with these sample cases to be made by an interviewer who can easily transition to Spanish language if necessary. A total of 7,674 participants completed the survey. We obtained approval for the current study from Howard University Institutional Review Board (IRB-11-MED-53) and downloaded the data from HINTS website.

\section{Exposure and outcome assessment}

Our analytic sample consisted of 4,299 respondents who were at least 50 years of age and answered questions regarding their places of birth and CRC screening behavior (3,960 USborn respondents, weighted population size $=74,618,632$; and 339 foreign-born respondents, weighted population size $=7,277,759)$. Survey participants answered whether they "strongly agree, somewhat agree, somewhat disagree, and strongly disagree" with statements such as "Screening finds cancer when it's easy to treat"; "There is not much you can do to prevent cancer"; "Behavior and lifestyle causes cancer"; "Cancer can be cured when detected early"; and "Everything causes cancer". They were also asked questions regarding their worries about cancer.
Respondents were asked when they had their most recent FOBT, sigmoidoscopy and colonoscopy. We defined being upto-date with CRC screening as the use of FOBT within 1 year, sigmoidoscopy within the last 5 years, or colonoscopy within the last 10 years.

\section{Statistical analysis}

HINTS data contained sample weights to obtain population-level estimates and a set of 50 replicate sampling weights to obtain the correct standard errors. Based on the recommendation from HINTS, we evaluated the effect of survey modes (mail and telephone) to determine whether a combined analysis was appropriate. There was no mode difference regarding place of birth $(\mathrm{P}=0.249)$. Therefore, we used the combined data for our analyses. We compared the demographic characteristics of those who were born in the United States with those who were foreign-born. We evaluated the association between place of birth (foreign- versus USborn) and being up-to-date with CRC screening. We also investigated being up-to-date with CRC screening guidelines relative to the cancer beliefs of respondents (in relation to cancer screening; cancer causes; cancer prevention; cancer fatalism; and cancer worry). The small sample size of foreignborn respondents precluded meaningful analysis of cancer beliefs stratified by place of birth. Therefore, we evaluated the association of cancer beliefs among our entire analytic cohort. We used logistic regression models to calculate the odds ratio (OR) with 95\% confidence interval (CI) in association with being up-to-date with CRC screening guidelines. Our full models included age, sex, race, body mass index, education, health insurance coverage, income and marital status. These were selected a priori, based on literature review. We used survey weight in all analyses to obtain population based estimates, hence we reported weighted percentages rather than arithmetic percentages. Variance estimations were performed with Taylor series linearization to account for complex survey design using STATA statistical software version 12.0, College Station, Texas.

\section{Results}

US-born respondents were older, mean age 64.0 years (95\%CI: 63.8-64.2) compared to mean age 61.4 years $(95 \% \mathrm{CI}$ : 60.1-62.6) of foreign-born respondents. The mean age using weighted survey analysis for continuous variables does not produce $\mathrm{P}$ value. Rather, it produces mean age and the 95\% CI. There is a notable difference in the mean age as evidenced by lack of overlap of the $95 \%$ CI. However, the "unweighted analysis" would have been: $\mathrm{P}=0.0035$ using non-parametric rank-sum test. US-born respondents were more likely to be non-Hispanic whites $(\mathrm{P}<0.001)$, had more formal education $(\mathrm{P}<0.001)$, more likely to have health insurance $(\mathrm{P}<0.001)$ and were more likely to have a history of smoking $(\mathrm{P}=0.0013)$. 
There was no difference in sex preponderance (Table 1). Being foreign-born was associated with a $35 \%$ statistically significant reduced odds of being current with CRC screening in the univariate analysis but the effect became attenuated after adjustments for potential confounders (OR 0.79; 95\%CI: 0.5 -1.24) (Table 2).

Our findings suggest that the opinion of respondents regarding cancer, influence their being current with CRC screening guidelines. Respondents who had a favorable opinion that cancer can be detected early and cured were more likely to be current, whereas those with fatalistic beliefs were less likely to be current with CRC screening guidelines (Table 3).

\section{Discussion}

We evaluated the association of place of birth (US- versus foreign-born) with being current with CRC screening guidelines. We found important differences by nativity in factors known to affect CRC screening. For example, there was a higher representation of Hispanics, lower formal education and higher percentage of respondents without health insurance coverage among foreign-born persons. Nonetheless, after taking these factors into consideration, our study is suggestive that in general, foreign-born adults in the US have lower uptake of CRC screening. We also evaluated the effect of cancer beliefs with compliance with CRC screening guidelines. We found that respondents who have positive opinion about cancer prevention were more likely to be current with CRC screening. The lower screening rates among foreign-born respondents may be related to a relative lack of organized or programmatic population based CRC screening in their countries of origin. Although HINTS did not collect data to ascertain the country of origin of foreign-born respondents, whether they migrated as adults or not and the time that has elapsed since migration, we speculate that foreign-born persons were probably less aware of CRC screening which may also be related to their poorer access to healthcare services. Overall, our study underscores the need for increased education of the population about CRC prevention, particularly among foreign-born persons.

Our findings corroborate a previous report by Goel et al [6]. In that study, the authors used data from the 1998 National Health Interview Survey and reported that foreign-born persons were less likely to be up-to-date with CRC screening with FOBT and sigmoidoscopy. This was prior to widespread use of colonoscopy as a screening modality. In recent times, colonoscopy is fast becoming the dominant screening modality with reduced use of other acceptable methods of CRC screening $[7,8]$. However, in our study, we evaluated the use of FOBT, sigmoidoscopy and colonoscopy and our findings are similar.

A low perceived risk of CRC which may be due to lack of knowledge about family history of CRC [12] in combination with inadequate knowledge of the efficacy of CRC screening has been reported to be associated with a reduced uptake of CRC screening [2,3]. Fatalism has been reported to be a psychological and sociocultural barrier and has been associated
Table 1 Comparison of the characteristics of respondents by place of birth

\begin{tabular}{|c|c|c|c|}
\hline & US-born & Foreign-born & P-value \\
\hline Sex & & & 0.188 \\
\hline Male & $1568(45.7)$ & $137(49.8)$ & \\
\hline Female & $2392(54.3)$ & $202(51.2)$ & \\
\hline Self-identified race & & & $<0.001$ \\
\hline White & $3300(83.5)$ & $130(29.3)$ & \\
\hline Black & $337(10.9)$ & $23(7.1)$ & \\
\hline Hispanic & $124(3.6)$ & $109(38.7)$ & \\
\hline Others & $115(2.1)$ & $72(24.9)$ & \\
\hline Level of education & & & $<0.001$ \\
\hline Less than high school & $373(15.1)$ & $66(30.9)$ & \\
\hline High school & $1,102(28.5)$ & $65(18.1)$ & \\
\hline Some college & $1,180(32.4)$ & $71(20.6)$ & \\
\hline College graduate & $1,297(24.1)$ & $136(30.3)$ & \\
\hline Smoking status & & & 0.0013 \\
\hline Never & $1,795(44.3)$ & $204(60.4)$ & \\
\hline Former & $1538(39.3)$ & $92(26.9)$ & \\
\hline Current & $575(16.4)$ & $35(12.7)$ & \\
\hline Income per year & & & 0.13 \\
\hline Less $<\$ 20,000$ & $600(19.1)$ & $68(23.4)$ & \\
\hline Less $<\$ 35,000$ & $618(18.9)$ & $62(22.2)$ & \\
\hline Less $<\$ 50,000$ & $488(14.5)$ & $24(8.1)$ & \\
\hline Less $<\$ 75,000$ & $637(19.1)$ & $54(21.3)$ & \\
\hline Greater $>\$ 75,000$ & $948(28.4)$ & $81(25.0)$ & \\
\hline Body mass index in $\mathrm{kg} / \mathrm{m}^{2}$ & & & 0.02 \\
\hline$<25$ & $1286(31.0)$ & $143(41.3)$ & \\
\hline $25-29$ & $1454(37.7)$ & $123(35.9)$ & \\
\hline$>30$ & $1182(31.3)$ & $71(22.9)$ & \\
\hline Has health insurance & & & $<0.001$ \\
\hline No & $260(7.8)$ & $44(16.1)$ & \\
\hline Yes & $3645(92.3)$ & $287(83.9)$ & \\
\hline
\end{tabular}

All percentages are weighted \%

Table 2 Univariate and multivariate analysis of association between place of birth and being up-to-date with colorectal cancer screening

\begin{tabular}{lccc} 
Nativity & $\begin{array}{c}\mathrm{N}(\mathrm{Wt} \% \\
\text { screened })\end{array}$ & $\begin{array}{c}\text { Univariate } \\
\text { OR }(95 \% \mathrm{CI})\end{array}$ & $\begin{array}{c}\text { Multivariate } \\
\text { OR }(95 \% \mathrm{CI})\end{array}$ \\
\hline US-born $(\mathrm{n}=3,960)$ & $2,594(63.3)$ & Reference & Reference \\
Foreign-born $(\mathrm{n}=339)$ & $208(52.8)$ & $0.65(0.50-0.85)$ & $0.79(0.50-1.24)$ \\
\hline
\end{tabular}

Adjusted for age, sex, race, body mass index, education, income, health insurance, and marital status

with lower uptake of FOBT screening [10]. In contrast, uptake of CRC screening is higher among US-born respondents and among those who believe that CRC screening is efficacious. 
Table 3 Association between cancer beliefs and being up-to-date with colorectal cancer screening

\begin{tabular}{|c|c|c|c|}
\hline Cancer belief & $\begin{array}{l}\text { Respondents screened, } \mathrm{N} \\
\text { (wt \% screen) }\end{array}$ & $\begin{array}{l}\text { Univariate } \\
\text { OR }(95 \% \mathrm{CI})\end{array}$ & $\begin{array}{l}\text { Multivariate } \\
\text { OR (95\% CI) }\end{array}$ \\
\hline \multicolumn{4}{|c|}{ Screening finds cancer when easy to treat } \\
\hline No $(n=197)$ & $87(45.2)$ & Reference & Reference \\
\hline Yes $(n=4,057)$ & $2,696(63.6)$ & $2.13(1.43-3.17)$ & $2.85(1.44-3.61)$ \\
\hline \multicolumn{4}{|c|}{ Not much you can do to prevent cancer } \\
\hline No $(n=3,135)$ & $2,095(63.8)$ & Reference & Reference \\
\hline Yes $(n=1,091)$ & $653(58.0)$ & $0.78(0.64-0.96)$ & $0.82(0.65-1.04)$ \\
\hline \multicolumn{4}{|c|}{ Behavior and Lifestyle causes cancer } \\
\hline No $(n=2,107)$ & $1,349(61.2)$ & Reference & Reference \\
\hline Yes $(n=2118)$ & $1,402(63.3)$ & $1.10(0.94-1.27)$ & $1.10(0.92-1.34)$ \\
\hline \multicolumn{4}{|c|}{ Cancer can be cured when detected early } \\
\hline No $(n=536)$ & $306(54.6)$ & Reference & Reference \\
\hline Yes $(\mathrm{n}=3691)$ & $2,451(63.6)$ & $1.46(1.16-1.82)$ & $1.56(1.20-2.00)$ \\
\hline \multicolumn{4}{|c|}{ Everything causes cancer } \\
\hline No $(n=2169)$ & $1,445(63.7)$ & Reference & Reference \\
\hline Yes $(n=2034)$ & $1,297(61.5)$ & $0.91(0.76-1.08)$ & $1.00(0.83-1.21)$ \\
\hline \multicolumn{4}{|c|}{ Worry about getting cancer } \\
\hline No $(n=2193)$ & $1,387(60.7)$ & Reference & Reference \\
\hline Yes $(n=2073)$ & $1,396(64.2)$ & $1.16(0.98-1.37)$ & $1.34(1.10-1.61)$ \\
\hline
\end{tabular}

Adjusted for age, sex, race, body mass index, education, income, health insurance, and marital status

\section{Summary Box}

\section{What is already known:}

- There is wide spread immigration to Europe andNorth Americaat present time

- Colorectal cancer susceptibility changes with migration

- Cancer beliefs affect colon cancer screening uptake

\section{What the new findings are:}

- Immigrants are less likely to be compliant with colon cancer screening guidelines

- Optimism about cancer detection and treatment enhances uptake of cancer screening

- Cancer fatalism reduces colon cancer screening uptake

This aligns with the health belief model which suggests that people are apt to act when they believe they are susceptible to the condition (perceived susceptibility), believe the condition has serious consequences (perceived severity), believe taking action would reduce their susceptibility to the condition or its severity (perceived benefits), believe costs of taking action (perceived barriers) are outweighed by the benefits, are exposed to factors that prompt action (e.g. a television advertisement or a reminder from one's physician), and are confident in their ability to successfully perform an action (self-efficacy) [13]. Therefore, regularly providing information about advances in cancer prevention and management will be important in reducing cancer fatalistic beliefs and thus improve CRC screening uptake among US adults. Immigrants should be encouraged to discuss their diagnosis with members of their family so that they may become more aware of their individual risk so that persons at higher risk of this deadly, but largely preventable disease can take important steps to mitigate their risks. A culturally sensitive approach tailored to foreign-born individuals may also increase their acceptance and subsequent participation in CRC screening.

There are some notable strengths of our study. We used a large, nationally representative sample of US adults. The 2007 iteration of HINTS was conducted in English and Spanish with two communication modalities (telephone and mail), thereby ensuring a broad reach of the population. However, our study is limited by the fact that it was based on self-report and there was no medical record review to validate CRC screening. There was relatively small number of foreign-born persons. Percentage of foreign-born in our study is $9 \%$, while the actual percentage of foreign-born in the US is $13 \%$ [14]. Overall response rate of HINTS 2007 was modest; $24 \%$ for the random digital dial sample and $31 \%$ for mail sample. Furthermore, there was no information on the regions of the world foreignborn respondents migrated from to the United States. 
In conclusion, suboptimal uptake of CRC screening may contribute to increased risk of CRC among immigrants in this modern era of widespread CRC screening. It is important for healthcare providers to inquire about cancer beliefs of all patients to inform cancer prevention education intervention and counseling.

\section{References}

1. Stemmermann GN, Mandel M, Mower HF. Colon cancer: its precursors and companions in Hawaii Japanese. Natl Cancer Inst Monogr 1979;53:175-179.

2. American Cancer Society. Colorectal Cancer Facts \& Figures, 2011-2013. American Cancer Society, 2011 pg 5 -8 Accessed July 13, 2015, at http://www.cancer.org/research/cancerfactsfigures/ colorectalcancerfactsfigures.

3. van Dam L, Korfage IJ, Kuipers EJ, et al. What influences the decision to participate in colorectal cancer screening with faecal occult blood testing and sigmoidoscopy? Eur J Cancer 2013;49:2321-2330.

4. Miles A, Rainbow S, von Wagner S. Inequalities in participation in an organized national colorectal cancer screening programme. Cancer Epidemiol Biomarkers Prev 2011;20:2132-2140.

5. Kobayashi LC, Wardle J, von Wagner C. Limited health literacy is a barrier to colorectal cancer screening in England. Prev Med 2014;61:100-105.

6. Goel MS, Wee CC, McCarthy EP, Davis RB, Ngo-Metzger Q, Phillips RS. Racial and ethnic disparities in cancer screening: the importance of foreign birth as a barrier to care. J Gen Intern Med 2003; 18:1028-1035.

7. Doubeni CA, Laiyemo AO, Reed G, Field TS, Fletcher RH. Socioeconomic and racial patterns of colorectal cancer screening among Medicare enrollees in 2000 to 2005. Cancer Epidemiol Biomarkers Prev 2009;18:2170-2175.

8. Subramanian S, Amonkar MM, Hunt TL. Use of colonoscopy for colorectal cancer screening: evidence from the 2000 National Health Interview Survey. Cancer Epidemiol Biomarkers Prev 2005; 14:409-416.

9. Lykins ELB, Graue LO, Brechting EH, Roach AR, Gochett CG, Andrykowski MA. Beliefs About Cancer Causation and Prevention As a Function of Personal and Family History of Cancer: A National, Population-Based Study. Psychooncology 2008;17:967-974.

10. Powe BD. Fatalism among elderly African Americans. Effects on colorectal cancer screening. Cancer Nurs 1995;18:385-392.

11. Cantor D, Coa K, Crystal-Mansour S, Davis T, Dipko S, Sigman R. "Health Information National Trends Survey (HINTS) 2007: Final Report.” Hints.cancer.gov. 2009. Available at http://hints.cancer. gov/docs/HINTS2007FinalReport.pdf. Last accessed 12 April, 2016.

12. Orom H, Kiviniemi MT, Underwood W, Ross L, Shavers VL. Perceived Cancer Risk: Why Is It Lower Among Non-Whites than Whites? Cancer Epidemiol Biomarkers Prev 2010;19:746-754.

13. National Cancer Institute. Theory at a glance, $2^{\text {nd }}$ edition. US Department of Health and Human Resources, National Institute of Health: 2005, p. 13.

14. Grieco EM, Acosta YD, de la Cruz GP, et al. The foreign-born population in the United States: 2010 American Community Survey Reports. Available at: http://www.census.gov/prod/2012pubs/acs19.pdf. Last visited 12 April, 2016, pp. 1-3. 